\title{
The influence of strength training on the sports performance of athletes in rowing in the context of digitalization of society system
}

\author{
Olga Brovashova*, Tatiana Tumasyan, Elena Nemtseva, and Natalia Stepicheva \\ Don State Technical University, 344000, Rostov-on-Don, Russia
}

\begin{abstract}
The work is devoted to the analysis of the importance of strength training on sports results in rowing. The important role of strength training is noted not only in the preparatory, transitional, but also in the competitive period of training. On the basis of research materials, the significance and effectiveness of strength training in the training process in rowing has been proved. It was found that athletes performing properly planned strength training show better results in rowing. The methods of planning strength training in the annual macrocycle of sports training are described.
\end{abstract}

\section{Introduction}

Strength training is an integral part of the training process for elite rowers in rowing, which accounts for $10-20 \%$ of the total training time. The development of such a quality as strength is one of the main components of the general physical training of an athlete - a rower [1]. The question of the need for strength training in rowing was raised in the early sixties of the nineteenth century by N. Wilkins (1961), Archibald McLaren (1866). The quote of the famous English coach Steve Ferburn, who spoke about strength training in the thirties of the 20th century: "Rowing prepares for lifting weights, and lifting weights will prepare for rowing" was very popular, and for some coaches and a guide to action. The development of strength in rowing is devoted to numerous works of Soviet, Russian and foreign specialists. One of the pillars of practicing trainers in the post-war years, GS Losavio rightly noted that one of the reserves for increasing the boat speed is to increase the seated stroke. Strength training D. Rayton - director of the British Rowing Association in the $50 \mathrm{~s}-70 \mathrm{~s}$ - called "the key to increasing speed" and, not without reason, argued that the most brilliant example for international teams is the "Ratzebourg Model" - the training methods of Karl Adam and his team - winners of the XVII Olympic Games in Rome. The team of the "Vesper" club (USA) won the 18th Olympiad. The coach, who, one of the former students of K. Adam, further intensified the methods of developing physical fitness. And at the XIX Olympic Games, German rowers regained the title of Olympic champions. The main emphasis in the Ratzeburg training program is placed on intense training in the preparatory period, aimed at developing strength and strength endurance. Moreover, the

*Corresponding author: olivka1103@yandex.ru 
development of strength is extremely important. Currently, resistance training is recognized as the main means for developing strength and changing the quality of muscles in the desired direction in sports practice. This is confirmed by numerous experimental works and studies.

Unfortunately, in the modern Russian national team, testing, research and recommendations to coaches are almost never carried out, so it was not possible to take strength indicators during control trainings from S. Fedorovtsev, Vl. Ryabtseva. Coaches have to focus on the curve and performance of Concept 2. aimed at developing strength and strength endurance. Moreover, the development of strength is extremely important. Currently, resistance training is recognized as the main means for developing strength and changing the quality of muscles in the desired direction in sports practice. This is confirmed by numerous experimental works and studies. Unfortunately, in the modern Russian national team, testing, research and recommendations to coaches are almost never carried out, so it was not possible to take strength indicators during control trainings from $\mathrm{S}$. Fedorovtsev, Vl. Ryabtseva. Coaches have to focus on the curve and performance of Concept 2. aimed at developing strength and strength endurance. Moreover, the development of strength is extremely important. Currently, resistance training is recognized as the main means for developing strength and changing the quality of muscles in the desired direction in sports practice. This is confirmed by numerous experimental works and studies.Unfortunately, in the modern Russian national team, testing, research and recommendations to coaches are almost not carried out, so it was not possible to take strength indicators during control trainings with S. Fedorovtsev, Vl. Ryabtseva. Coaches have to focus on the curve and performance of Concept 2. Currently, resistance training is recognized as the main means for developing strength and changing the quality of muscles in the desired direction in sports practice. This is confirmed by numerous experimental works and studies. Unfortunately, in the modern Russian national team, testing, research and recommendations to coaches are almost not carried out, so it was not possible to take strength indicators during control trainings with S. Fedorovtsev, Vl. Ryabtseva. Coaches have to focus on the curve and performance of Concept 2. Currently, resistance training is recognized as the main means for developing strength and changing the quality of muscles in the desired direction in sports practice. This is confirmed by numerous experimental works and studies. Unfortunately, in the modern Russian national team, testing, research and recommendations to coaches are almost never carried out, so it was not possible to take strength indicators during control trainings from S. Fedorovtsev, Vl. Ryabtseva. Coaches have to focus on the curve and performance of Concept 2. Fedorovtseva, V1. Ryabtseva. Coaches have to focus on the curve and performance of Concept 2. Fedorovtseva, V1. Ryabtseva. Coaches have to focus on the curve and performance of Concept 2.

\section{Materials and methods}

Purpose of the research: to test the proposed program of strength training in the annual macrocycle of sports training among rowers and experimentally check possible increases in sports results in rowing with an increase in the value of strength training of an athlete. To study the role of strength training not only in the preparatory, transitional, but also in the competitive period of training. To investigate the importance and effectiveness of strength training in the training process in rowing. 


\section{Research methodology and organization}

The study was conducted on the basis of the Don rowing canal (Rostov-on-Don) in the period 2018-2019. In total, 10 people, members of the DSTU national team, took part in the study, of which the bulk ( 8 people) with the first sports category and two candidates for the master of sports of Russia (CCM).

One of the main methods of strength development is the choice of the magnitude of the weights, then the number of movements (repetitions) and the number of approaches in one exercise (positions), the number of exercises (positions, stations), rest between approaches. The highest level of manifestation and development of strength is observed with a dynamic overcoming mode of muscle work.

Resistance exercise is a valuable tool for developing strength, speed strength, and strength endurance. The magnitude of the weights was calculated for each athlete individually as a percentage of the one-time max (PM), and then, with the method of maximum stress, the magnitude of the weights: From 90 to $95 \%$ PM; The number of movements (repetitions): 2-4. And for the development of strength endurance, the weight is burdening:

$70 \%+/-5 \%$ of $1 \mathrm{PM}$ total endurance is developed with a weight weighted down 40 $50 \%$ of $1 \mathrm{PM}$ with a significant increase in the number of reps per set.

When planning a one-year training cycle in the strength training unit, it was distributed as follows:

1. Transition period.

a) The retraction stage (October - November) - testing of maximum strength, strength endurance was carried out, as well as a block for the development of strength qualities. The main task is to strengthen the muscle corset, the development of speed-strength qualities.

b) $1 \mathrm{st}$ preparatory stage (November - December). The main task

- development of maximum strength. The main control measures are testing the level of maximum strength.

c) 2nd preparatory stage (January - February). The main task is to develop strength endurance. The main control measures are testing of maximum strength.

2. Competitive period.

a) 1 st competition stage (Febral - April). The main task - development of special forces.

b) 2nd competition stage (April - May). The main task is to develop special forces.

The following tests were determined: Run - $3000 \mathrm{~m}$; pulling (lying deadlift) barbell weighing $45 \mathrm{~kg}$ (man), lying with his chest on the board for 5 minutes; jumping on a curbstone $60 \mathrm{~cm}$ high in 1 minute; squats with a barbell on the shoulders (max); squats with a kettlebell $24 \mathrm{~kg}$ in $5 \mathrm{~min}$. These tests made it possible to evaluate athletes in terms of strength, speed, strength endurance, and general endurance. Special endurance and ranking of all (without exception) athletes passed (assessed) through races in 2 (rowers); in 1 (greenhouses).

As a specific parallel rowing workout, an eight week period of strength training with high load (70-90\% of maximum) was added to reveal a greater improvement in rowing performance. For athletes who train for both strength and endurance at the same time, three weekly strength training sessions have been recommended. Accordingly, rowers, as a rule, performed two

- Three strength training sessions per week, with the final session often taking place 2448 hours before training on the water, rowing machines or even a competition. 


\section{Results}

Standard rowing competitions are held at a distance of $2000 \mathrm{~m}$ and last 5.5-7.0 minutes. The dominant energy contribution to the rowing race is aerobic metabolism; however, anaerobic qualities such as muscle strength and power are also seen as important predictors of overall performance. Studies have shown that strength indicators among academic rowers correlate well with time indicators on a rowing ergometer at a distance of 2000 meters. These findings suggest that strength is the most important physical component in rowing. Indeed, maximum strength, starting power and muscular endurance at medium distances $(2000 \mathrm{~m})$ were defined as the limiting factors for achieving optimal rowing results. It has been experimentally proven that rowing qualities are highly correlated with maximum strength, so it seems appropriate for rowers to concentrate on developing these qualities. Maximum strength and power have been shown to develop optimally with significant resistance training with minimal repetitions in each set of exercises.

The table below shows the averaged data of strength training testing of athletes at the initial stage of the study and at the end of the one-year cycle of strength training. And also a comparative analysis of the results of academic rowers on the rowing ergometer at a distance of 2000 meters is similar at the beginning and at the end of the proposed program.

Table1. Indicators of the level of strength training for the sports result of athletes in rowing

\begin{tabular}{|c|c|c|c|}
\hline Tests & $\begin{array}{c}\text { Initial } \\
\text { stage of } \\
\text { research }\end{array}$ & $\begin{array}{c}\text { The final } \\
\text { result of the } \\
\text { study }\end{array}$ & $\begin{array}{c}\text { Change in the } \\
\text { average result in } \\
\text { percentage }\end{array}$ \\
\hline Running $3000 \mathrm{~m}(\mathrm{~min}, \mathrm{~s})$ & $13.10 \pm 0.27$ & $12.05 \pm 0.10$ & Increased by $8.01 \%$ \\
\hline Deadlift $(5 \mathrm{~min})$ & $119 \pm 8$ & $140 \pm 10$ & Increased by $17.6 \%$ \\
\hline Jumping on the curbstone $(1 \mathrm{~min})$ & $27 \pm 5$ & $36 \pm 3$ & Increased by $33.3 \%$ \\
\hline KettlebellSquat $24 \mathrm{~kg}(5 \mathrm{~min})$ & $125 \pm 10$ & $144 \pm 6$ & Increased by $15.2 \%$ \\
\hline Rowing machine $2000 \mathrm{~m}(\mathrm{~min}, \mathrm{~s})$ & $7.10 \pm 0.18$ & $6.47 \pm 0.20$ & Increased by $9.7 \%$ \\
\hline
\end{tabular}

An improvement in the test results can be noted: running 3000 meters along the stadium track from 11 minutes 58 seconds to 12 minutes 12 seconds; thrust lying $45 \mathrm{~kg} \mathrm{130-150}$ times; jumping on the curbstone 33-39 times; kettlebell squat 138-150. Rowing requires a high proportion of maximum strength combined with high muscle speed and endurance. Maximum strength grows faster during special strength exercises with weights than directly during rowing, since during such exercises you can achieve a higher tension of individual muscle groups (there is no effect of boat speed).

\section{Discussions}

On the basis of research, we can talk about the relationship between the biochemical basis of the quality of strength, the content and properties of the structural proteins of muscles, especially the release of the contractile protein myosin, which determines the body's ability to quickly mobilize the chemical energy of ATP and convert it into mechanical energy. Maximum strength characterizes the athlete's ability to manifest the highest, maximum muscular efforts.

Research into specific parallel rowing workouts has shown the effectiveness of adding eight weeks of high resistance strength training. However, it should be borne in mind that intense strength training can lead to the development of "residual fatigue" and suboptimal adaptations in rowing exercises, compared with lower volume strength training.

Thus, in order to achieve optimal adaptation and performance indicators, the use of strength training for rowers requires careful implementation and control. 


\section{Conclusions}

Taking into account the results obtained, it can be concluded that strength training, along with the level of development of strength qualities, is an important component in the structure of the preparatory and competitive stages in rowing. Taking into account the basic principles of building strength training, high-quality planning in various periods of one-year training are the key factors leading to an increase in sports results in rowing.

Thus, developing maximum strength and improving the quality of the individual stroke contributes to the creation of a reserve of power and constitutes an important reserve for improving results in rowing.

The authors express their gratitude to the rector of DSTU B.Ch. Meskhi for the attention and support provided by the Don State Technical University in the development of student rowing and in the formation of young athletes on the way to achieving high results.

\section{References}

1. E.V. Khromin, Theory and Practice of Physical Culture 1, 3-5 (2019).

2. A.V. Voronkov, I.N. Nikulin, A.A. Kolesnikov, D.E. Nikulina, Theory and Practice of Physical Culture 5, 11 (2019).

3. T.J. Kauh, Preventive Medicine 130,105894 (2020).

4. S.G. Farris, E.K. Burr, M.M. Kibbey, A.M. Abrantes, A.M. DiBello, Mental Health and Physical Activity 19, 100346 (2020).

5. Pooja S. Tandon, Melanie Klein, Brian E. Saelens, Dimitri A. Christakis, Mental Health and Physical Activity 15, 17-21 (2018).

6. A. Ivanova, N.V. Ryzhkin, I.A. Stepanova, E.A. Nurdygi, Physical education: education, training 2 (79), 53-56 (2019).

7. A. Ivanova, O.Y Brovashova, Adaptation and development of the physical culture and sports complex of the GTO in accordance with changes in society, In the collection: Innovative transformations in the field of physical culture, sports and tourism. Collection of materials of the XXI All-Russian scientific and practical conference, 287292 (2018).

8. Pooja S. Tandon, Melanie Klein, Brian E. Saelens, Dimitri A. Christakis, Mental Health and Physical Activity 15, 17-21 (2018).

9. Samira Rahimi, Maghsoud Peeri, Mohammad Ali Azarbayjani, Leila Anoosheh, Physiology \& Behavior 226, 113130 (2020).

10. Tatiana Stepanova, R.M. Olkhovsky, E.A. Vashchenko, N.V. Ryzhkin, Theory and practice of physical culture 8, 98-99 (2018).

11. Janet E. Simon, Carrie L. Docherty, Journal of Science and Medicine in Sport 21 (12), 1206-1209 (2018).

12. T. Wisbey-Roth, Journal of Science and Medicine in Sport 22 (1), 1 (2019).

13. Barnett S. Frank, Anthony C. Hackney, Claudio L. Battaglini, Journal of Science and Medicine in Sport 22 (1), 29-34 (2019).

14. J. Luke Pryor, Riana R. Pryor, Lesley W. Vandermark, Elizabeth L. Adams, Journal of Science and Medicine in Sport 22 (1), 117-122 (2019).

15. M. Shestakov. S. Agafonov, Scientific notes of the University. P.F. Lesgaft 5 (147), 199-203 (2017). 